\title{
Coulisses
}

Revue de théâtre

13 | Hiver 1996

Varia

\section{La Princesse au petit pois, d'après Hans Christian Andersen, conte musical}

Espace Scène Nationale ; 24-25 novembre 1995

Jean-Luc Clairet

\section{CpenEdition}

\section{Journals}

Édition électronique

URL : http://journals.openedition.org/coulisses/4342

DOI : $10.4000 /$ coulisses. 4342

ISSN : 2546-9460

\section{Éditeur}

Presses universitaires de Franche-Comté

Édition imprimée

Date de publication : 1 janvier 1996

Pagination : 75-76

ISSN : 1150-594X

\section{Référence électronique}

Jean-Luc Clairet, «La Princesse au petit pois, d'après Hans Christian Andersen, conte musical », Coulisses [En ligne], 13 | Hiver 1996, mis en ligne le 15 mars 2019, consulté le 05 octobre 2020. URL: http://journals.openedition.org/coulisses/4342 ; DOI : https://doi.org/10.4000/coulisses.4342

Ce document a été généré automatiquement le 5 octobre 2020.

Coulisses 


\section{La Princesse au petit pois, d'après Hans Christian Andersen, conte musical}

Espace Scène Nationale ; 24-25 novembre 1995

Jean-Luc Clairet

\section{L'ensemble Justiniana}

1 Et dire qu'il existe encore en Franche-Comté des gens qui ne connaissent pas encore Charlotte Nessi, qui ne connaissent pas encore l'Ensemble Justiniana... lequel a pourtant vu le jour au cœur de l'été 82. Depuis, il a envahi les lieux qui nous sont chers ici et là, il y a fait naître des images qui n'ont pas cessé de nous accompagner : Didon et Énée, Le Petit Ramoneur, Journal d'un usager de l'espace, Quichotte, Naïs, La Petite Messe solennelle, La Petite Sirène, L'Arche de Noé, Vol au-dessus de l'océan... Autant de titres qui jalonnent un parcours mémorable.

Sans oublier cet incomparable Jasager («Celui qui dit oui ») de Kurt Weill que Didier Brunei vient d'inscrire en coup d'envoi de sa première saison à la tête de l'Opéra Théâtre au cours d'un passionnant travail autour de Brecht et qui vient d'être repris triomphalement à l'Opéra Bastille.

Oui, l'Ensemble Justiniana s'exporte et c'est justice. Cependant il serait logique de tout faire pour que son œuvre se poursuive ici. Le principe en est simple: à partir de l'imagination féconde de son initiatrice, sont mêlés professionnels et amateurs autour d'un travail où musique et théâtre sont intimement concernés et ce du début de la conception d'un spectacle (ou presque) à son achèvement. 


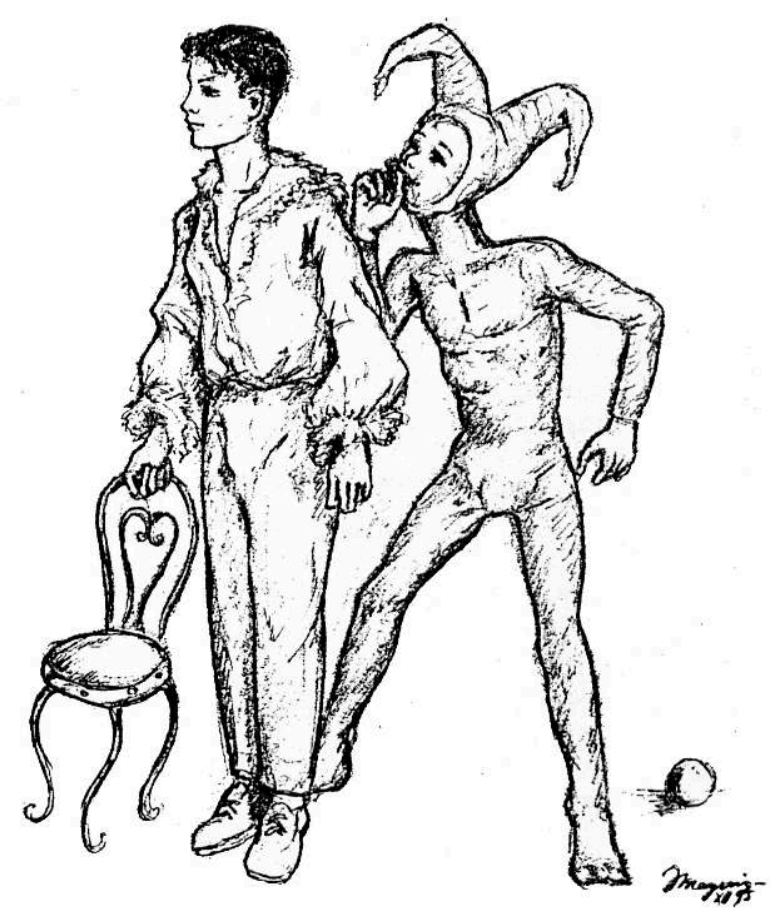

\section{Un centre d'art lyrique junior}

Plus de dix ans après, des lignes fortes se dégagent au fil des genres abordés (opéra, opéra didactique, opéra pour enfants, opéra-jazz) mais une surtout frappe à l'évidence : ce travail inlassable et vraiment beau autour du monde de l'enfance, un travail d'où toute mièvrerie est systématiquement bannie et qui pourtant enchante.

Il semble presque aller de soi qu'aujourd'hui l'Ensemble Justiniana ait la volonté de créer un centre d'art lyrique junior pour ce public d'opéra de demain. Dans cette perspective, depuis deux ans, l'Ensemble Justiniana lance sans filet sur la scène lyrique des acteurs et des chanteurs souvent quasi recueillis au berceau, toutes couleurs confondues, ce qui engendre une fraternité rare sur la scène lyrique, et ce avec une maîtrise si confondante et une réaction publique si jubilatoire que l'on n'a plus envie de savoir où sont les professionnels dans un tel scénario. A tel point que dans La Princesse au petit pois (l'opus 2 après Guys \& Dolls présenté l'an passé) on doute presque que la chanteuse qui joue la reine mère soit réellement l'adulte qu'elle est, intégrée à l'ensemble, plutôt qu'une adolescente qui aurait poussé plus vite que les autres.

\section{Deux soirs de bonheur}

La Princesse au petit pois a été jouée à guichets fermés à l'Espace Scène Nationale de Besançon (une des premières scènes a avoir fait confiance à Charlotte Nessi et à son équipe). Deux soirs de bonheur sans mélange dans un spectacle en cinémascope enchâssé dans les beaux éclairages de Gérard Champlon et les costumes variés et irrésistibles de François Tomsu. 
4 Deux heures et demie d'une succession de clins d'œil, qui revisite notre enfance, qui se permet de décortiquer au scalpel de l'humour le pouvoir des mères abusives et le silence des pères.

Sur la scène de l'Espace c'est au propre comme au figuré un défilé de moments délectables : la folle dégustation d'alcool qui clôt la première partie en est le moment le plus irrésistible mais on n'aura garde d'oublier les rêves nocturnes du prince, ou ces chutes de matelas en folie ou encore cette logorrhée maternelle au débit parodique.

Devant ce tournoiement d'images on envie le bonheur des acteurs en imaginant même la folie contagieuse qui doit s'activer en coulisses avant chaque enchaînement. On se réjouit aussi de la complicité qui éclate entre le metteur en scène et son inventive chorégraphe Christine Marneffe sans oublier l'excellent Allan Scott Prouty qui fait des merveilles dans la fosse et grâce auquel les chanteurs ont acquis une prononciation anglaise dont l'aplomb frise l'excellence.

Les enfants de Franche-Comté ont bien de la chance. Bref le genre de soirée que l'on souhaite à tous ses voisins. Ainsi qu'à tous ceux qui ne connaissent pas encore l'Ensemble Justiniana et Charlotte Nessi. 